\title{
El impacto de la publicidad con equidad de género en la decisión de compra de los millennials
}

The impact of advertising with gender equality in the millennials' purchase decision

Jovanna Nathalie Cervantes-Guzmán

Universidad de Guadalajara, México

José G. Vargas-Hernández ${ }^{2}$

Universidad de Guadalajara, México

Guillermo Vázquez-Ávila ${ }^{3}$

Universidad de Guadalajara, México

\section{Para citar este artículo}

Artículo de investigación

Fecha de recepción: 15 de mayo de 2018 Fecha de aceptación: 27 de agosto de 2018

Cervantes-Guzmán, J. N., Vargas-Hernández, J. G., y Vázquez-Ávila, G. (2018). El impacto de la publicidad con equidad de género en la decisión de compra de los millennials. Revista Campos en Ciencias Sociales, 6(2), 49-93. Bogotá D.C., Colombia: Universidad Santo Tomás. DOI: https://doi.org/10.15332/ s2339-3688.2018.0002.02

1 Magíster en Dirección de Mercadotecnia. Correo electrónico: nathalie.cervantes34@gmail.com

2 Magíster en Administración de Negocios, Ph. D. en Administración Pública. Correo electrónico: josevargas@ cucea.udg.mx

3 Ph. D. en Ciencias Administrativas. Correo electrónico: gvazquez@cucea.udg.mx 


\title{
RESUMEN
}

Este artículo se propone analizar el impacto de la publicidad con equidad de género en la decisión de compra de los millennials bajo el supuesto de que la publicidad con mensajes positivos en la equidad de género logra un mayor efecto que aquella que es sexualizada. También se analizan los principales motivos por los cuales las empresas siguen manejando lenguajes de esta índole, además de que se enfatiza sobre la importancia de utilizar este tipo de lenguajes y las consecuencias que podría tener el no hacerlo. Se estudian del mismo modo las generaciones y se explican por qué el segmento determinado para su estudio es el mejor para poder captar y aceptar este tipo de información.

Palabras clave: publicidad, equidad de género, feminismo, millennial.

\begin{abstract}
This article aims to analyze the impact of advertising with gender equity in the millenials' purchase decision under the assumption that advertising with positive messages in gender equity achieves a greater effect than that which is sexualized. The main reasons why companies continue to use languages of this type are also analyzed, as well as emphasizing the importance of using such languages and the consequences of not doing so. Also, generations are studied, as well as it is explained why the segment determined for its study is the best to capture and accept this kind of information.
\end{abstract}

Keywords: Advertising, gender equality, feminism, millennial. 
Jovanna Nathalie Cervantes-Guzmán, José G. Vargas-Hernández y Guillermo Vázquez-Ávila

\section{INTRODUCCIÓN}

El feminismo ha estado presente a lo largo de la historia de la humanidad. Lo podemos corroborar con los escritos de protesta que surgieron en 1601 (Ritzer, 1997). El feminismo como movimiento se inició años atrás y continúa en la actualidad buscando el empoderamiento femenino con el objetivo de lograr una equidad de género, eliminando la violencia y las discriminaciones para que hombres y mujeres tengan las mismas oportunidades. Muchos han sido los avances, sin embargo, aún no se logra llegar a este objetivo. La publicidad podría ser uno de los responsables, que sigue promoviendo conductas deplorables con violencia, sexismo y machismo (Suárez, 2013). Es por ello que el tema de la presente investigación se enfoca en la búsqueda de spots publicitarios que utilicen un lenguaje responsable y que promuevan la equidad de género, para evaluar su efectividad en un determinado público.

Esta investigación toma de referencia principalmente a las de Rincón y Velandia (2013) y Suárez (2013), quienes en sus aportes analizan una serie de spots, para ello crean una herramienta que es un pequeño cuestionario que toma en cuenta cosas como el vocabulario, los personajes, la escenografía y el mensaje que se plantea dar. Así también, se tomaron las investigaciones de Galvis (2017) sobre la publicidad sexista en bebidas alcohólicas, donde no solamente analiza los spots sino que los muestra a un determinado segmento de estudiantes. Sin embargo, se encontraron algunos vacíos de literatura al no haber investigaciones mexicanas sobre estos temas.

Se plantea aportar una de las primeras investigaciones mexicanas sobre los estereotipos de género en la publicidad además de demostrar la efectividad de anuncios con lenguaje positivo en la equidad de género, con el fin de lograr concientización en las empresas y en el país para la creación de leyes.

El propósito de la investigación es el de comprobar la efectividad de los spots publicitarios que se ven en Facebook, YouTube e Instagram y que contienen un lenguaje positivo respecto a la equidad de género, para corroborar su efectividad en mujeres de 25 a 30 años que tengan un trabajo estable y que radiquen en el municipio de Zapopan (Jalisco, México). El problema está en la falta de concientización de la población sobre temas de estudios de género y equidad, además de la negación 
en transmitir este tipo de mensajes por parte de las marcas, pues estas no envían mensajes acordes a la equidad de género debido a que, se cree, esto podría tener un impacto negativo en las ventas, por ejemplo. La presente investigación plantea mostrar que un spot publicitario es más efectivo cuando contiene mensajes positivos en la equidad de género.

\section{Planteamiento del problema}

La publicidad está presente en cada uno de nuestros días, se estima que las personas percibimos aproximadamente 3000 impactos publicitarios por día (García, Manzano y Parredo, 2012). Esta conforma los hábitos de consumo, gustos, modos de vida, actitudes y estereotipos sociales de los consumidores (Porath, Vergara, Gómez y Labarca, 2017). Está comprobado que la publicidad no solamente refleja la cultura, sino que también la influencia, plasmando y definiendo los roles de género de nuestra sociedad (Schudson, 1986); como por ejemplo, los comerciales que aún muestran únicamente a las mujeres como amas de casa y a los hombres como fuertes empresarios.

A pesar de que el medio ha querido remediar la situación y apuntar a mostrar roles más equilibrados y equitativos, lo único que ha conseguido es la creación de spots con mensajes micromachistas, en los que se muestra al hombre como alguien incapaz de realizar las tareas del hogar si no hay una mujer que le apoye (Suárez, 2013). Para lograr una comunidad feminista en donde haya equidad de género, es necesario hacer cambios en la ideología de la sociedad, y una forma de iniciar esto es a través de los mensajes publicitarios que representan y moldean nuestras sociedades (Fernández, 2017). Sin embargo, existe un cuestionamiento por parte de las marcas y de las empresas creadoras de los spots publicitarios. Fernández (2017) establece: "los roles de género en la publicidad permiten que la audiencia se sienta identificada con lo que ve, al lograr que el consumidor se identifique se logra la compra”.

Es decir, no se utilizan spots con lenguaje feminista debido a que existe la creencia de que no se venderían los productos de la misma manera como sucede con los 
Jovanna Nathalie Cervantes-Guzmán, José G. Vargas-Hernández y Guillermo Vázquez-Ávila

spots estándar, lo que evidencia cómo la sociedad además de estar dividida por clases sociales también está dividida por el género (Duarte Cruz y García-Horta, 2016). En algunos países más desarrollados en este tema se han implementado leyes para el cuidado de la equidad de género en la publicidad. Tal es el caso de la ley para la promoción de la igualdad de género en Andalucía (España), referenciado por el Instituto Andaluz de la Mujer (2007). El artículo 57 de esta ley establece: "Los poderes públicos de Andalucía promoverán la transmisión de una imagen igualitaria, plural y no estereotipada de los hombres y de las mujeres en todos los medios de información y comunicación”.

En cuanto a México, todas las leyes establecidas en el reglamento de la ley general de salud en materia de publicidad federal cuidan los aspectos físicos del producto y evitan los posibles fraudes que podrían llegar a ocurrir. La ley federal de protección al consumidor protege a este desde un área más burocrática; ninguna de las dos leyes vela por la equidad de género en el país a través de la publicidad, ni siquiera la reconoce como salud emocional, fomentando con esto la implementación de spots publicitarios con mensajes sexistas y machistas perpetuando estos roles en la sociedad.

La publicidad no ha permanecido constante, los cambios tecnológicos, generacionales y culturales la han orientado. Cada generación social cuenta con atributos diferentes, ya sea por la manera de vestirse, comunicarse o expresarse, además de que sus valores y creencias son diferentes (Dormoi, 2016); todo esto se deriva a la línea de tiempo en la que han nacido los consumidores y a los cambios tecnológicos de los que les ha tocado ser testigos. Por tal razón la publicidad se ha ido adaptando, no solo en la estructura de sus mensajes sino también en los medios empleados. Los millennials son conocidos como los nativos digitales, sin embargo, los centennials se reconocen como la generación que quiere la información inmediata (Dormoi, 2016).

De acuerdo con el estudio "Los hábitos de los usuarios de Internet en México 2017" llevado a cabo por la Asociación de Internet.mx, el 70 \% de los mexicanos cuentan con Internet; el $83 \%$ de este total utiliza su tiempo libre para consultar redes sociales, las más utilizadas son Facebook (95 \%), YouTube (72 \%) e Instagram (59\%); además los usuarios pasan el 38 \% de su tiempo conectados a Internet en alguna red 
social; razones por las cuales las marcas han desarrollado estrategias específicas para poder llegar de una manera más eficaz a su público objetivo y aprovechar el tiempo de atención que tienen de los consumidores, implementando anuncios publicitarios dentro de las redes sociales que provocarán un cambio en el rumbo y en el futuro de la publicidad. A pesar de los cambios tecnológicos las marcas no han modificado los mensajes con estereotipos sociales dentro de sus spots, generando y perpetuando una cultura y sociedad desigual, en términos de género, en México.

En la presente investigación se plantea mostrar que los anuncios en las redes sociales Facebook, YouTube e Instagram, con impacto positivo en la equidad de género, tienen mejores resultados en las ventas a diferencia de los que no los tienen. Se expone en principio, una revisión del estado del arte con fuentes de artículos científicos de investigaciones previas en Chile, Colombia y España. Posteriormente se realiza una búsqueda y comparación de spots actuales en estas redes sociales, con el fin de hacer una crítica sobre su estructura, basada en los análisis teóricos previamente establecidos. Al final se exponen los resultados a partir de un grupo focal y una técnica proyectiva dirigida a mujeres de 25 a 30 años de la Zona Metropolitana de Guadalajara; esto con el fin de conocer su percepción de los spots con mensajes positivos en la equidad de género y también de los que no la tienen, a partir de allí se podrá evaluar su imagen hacia la marca después de haber visto el spot y su actitud de compra.

Al final se espera apuntar a la concientización sobre el impacto negativo que tienen los estereotipos en los spots publicitarios, y a su vez dar una alternativa de cómo los spots con mensajes positivos en la equidad de género obtienen mejores resultados que los que no cuidan estos aspectos. En ese sentido, esta investigación se planta como objetivo general comparar los anuncios con impacto positivo en equidad de género contra los que no la tienen y evaluar cuál tiene mejores resultados en las ventas, a partir de examinar los estereotipos sociales que están surgiendo en la actualidad a través de la publicidad en las redes sociales Facebook, YouTube e Instagram, así como también exponer cuáles son las características para lograr anuncios enfocados en las ventas con impacto positivo en equidad de género y mostrar la efectividad de la publicidad con impacto positivo en esta equidad. 


\section{HipóTESIS}

Variable dependiente: publicidad con mensaje positivo orientado a la equidad de género.

Variable independiente: decisión de compra.

La publicidad con mensajes positivos en equidad de género tiene un efecto positivo en la decisión de compra del consumidor, mientras que la publicidad con estereotipos no la tiene.

Hipótesis nula: la publicidad con mensajes positivos en equidad de género no tiene un efecto positivo en la decisión de compra del consumidor, mientras que la publicidad con estereotipos sí la tiene.

\section{Modelo}

En la Tabla 1 se pueden observar los factores que se desprenden de cada una de las variables del modelo que se utilizó para la presente investigación. 
Tabla 1. Modelo de investigación

\begin{tabular}{|c|c|c|c|c|}
\hline Variable & Definición & Dimensiones & Indicador & Autor \\
\hline \multirow{14}{*}{ Decisión de compra } & \multirow{14}{*}{$\begin{array}{l}\text { Según la valoración } \\
\text { de alternativas, } \\
\text { en esta fase el } \\
\text { consumidor lleva } \\
\text { a cabo la compra, } \\
\text { decidiendo la } \\
\text { marca, la cantidad } \\
\text { y dónde, cuándo } \\
\text { y cómo se efectúa } \\
\text { el pago (Kotler y } \\
\text { Armstrong, 2001). }\end{array}$} & \multirow{3}{*}{ Factor cultural } & Clase social & $\begin{array}{l}\text { (Kotler y Armstrong, } \\
\text { 2001) }\end{array}$ \\
\hline & & & Cultura & $\begin{array}{l}\text { (Kotler y Armstrong, } \\
\text { 2001) }\end{array}$ \\
\hline & & & Grupos de afinidad & $\begin{array}{c}\text { (Kotler y Armstrong, } \\
\text { 2001) }\end{array}$ \\
\hline & & \multirow{3}{*}{ Factor social } & $\begin{array}{l}\text { Grupos de } \\
\text { referencia }\end{array}$ & (Barboza, 2012) \\
\hline & & & Familia & $\begin{array}{l}\text { (Kotler y Armstrong, } \\
\text { 2001) }\end{array}$ \\
\hline & & & $\begin{array}{c}\text { Imagen ante la } \\
\text { sociedad (roles y } \\
\text { estatus) }\end{array}$ & $\begin{array}{l}\text { (Kotler y Armstrong, } \\
\text { 2001) }\end{array}$ \\
\hline & & \multirow{4}{*}{ Factor personal } & Edad & $\begin{array}{l}\text { (Kotler y Armstrong, } \\
\text { 2001) }\end{array}$ \\
\hline & & & Ocupación & $\begin{array}{l}\text { (Kotler y Armstrong, } \\
\text { 2001) }\end{array}$ \\
\hline & & & $\begin{array}{l}\text { Situación } \\
\text { económica }\end{array}$ & $\begin{array}{c}\text { (Kotler y Armstrong, } \\
\text { 2001) }\end{array}$ \\
\hline & & & Estilo de vida & $\begin{array}{c}\text { (Kotler y Armstrong, } \\
\text { 2001) }\end{array}$ \\
\hline & & \multirow{4}{*}{ Factor psicológico } & Motivación & (Maslow, 1958) \\
\hline & & & Personalidad & (Freud) \\
\hline & & & Percepción & (Freud) \\
\hline & & & Aprendizaje & (Freud) \\
\hline
\end{tabular}

Fuente: elaboración propia. 
Jovanna Nathalie Cervantes-Guzmán, José G. Vargas-Hernández y Guillermo Vázquez-Ávila

\section{ESTADO DEL ARTE}

Tabla 2. Revisión de la literatura

\begin{tabular}{|c|c|c|c|c|}
\hline Autor & Año & País & Muestra & Factores empíricos \\
\hline $\begin{array}{l}\text { Juan Carlos Rincón } \\
\text { Andrea Velandia }\end{array}$ & 2013 & Colombia & $\begin{array}{l}80 \text { comerciales } \\
\text { extraídos de los dos } \\
\text { canales privados con } \\
\text { mayor audiencia. }\end{array}$ & $\begin{array}{l}\text { Investigación ex post facto, siendo } \\
\text { los estereotipos las variables } \\
\text { independientes y el nivel de sexismo } \\
\text { la variable dependiente. } \\
\text { Realizaron un instrumento ad hoc, } \\
\text { con base en la escala de sexismo en la } \\
\text { publicidad. } \\
\text { Su objetivo era identificar las } \\
\text { representaciones y estereotipos de } \\
\text { género utilizados en los comerciales } \\
\text { que se transmitían por televisión. }\end{array}$ \\
\hline $\begin{array}{l}\text { Juan Carlos Suárez } \\
\text { Villegas }\end{array}$ & 2013 & Espańa & $\begin{array}{l}2 \text { comerciales con } \\
\text { enfoque en los } \\
\text { micromachismos. }\end{array}$ & $\begin{array}{l}\text { Investigación documental, } \\
\text { exploratoria. Analiza los estereotipos } \\
\text { de género, desmontando igualdades } \\
\text { ficticias. }\end{array}$ \\
\hline $\begin{array}{l}\text { Rodolfo Enrique } \\
\text { Galvis Reyes }\end{array}$ & 2017 & México & $\begin{array}{l}442 \text { estudiantes } \\
\text { universitarios, } \\
\text { hombres y mujeres. }\end{array}$ & $\begin{array}{l}\text { Su objetivo fue el de analizar los } \\
\text { efectos de los mensajes estereotipados } \\
\text { de la publicidad en la percepción } \\
\text { del consumidor y en la intención de } \\
\text { compra del mismo en la industria } \\
\text { cervecera. } \\
\text { Es una investigación descriptiva con } \\
\text { un estudio de percepción. }\end{array}$ \\
\hline
\end{tabular}

Fuente: elaboración propia.

En la Tabla 2 se pueden apreciar las principales fuentes en las que se basó la presente investigación, las cuales fueron dos investigaciones y un trabajo de tesis de maestría. La primera investigación de Rincón y Velandia (2013) tenía como objetivo identificar los estereotipos de género que se llevaban a cabo en los comerciales. Para ello crearon un instrumento basado en la escala de sexismo en publicidad, el cual se aplicó a una muestra de 80 comerciales extraídos de los dos canales privados de 
mayor audiencia en la televisión colombiana. Los resultados demostraron que el 48 $\%$ de los comerciales contaba con un alto nivel de sexismo, mientras que los demás tenían un nivel medio-alto. Esta investigación fue la primera en moldear el giro de este trabajo.

El trabajo de Suárez (2013) hace énfasis en los estereotipos de género, sin embargo, muestra otra causante: los micromachismos, una forma implícita de sexismo que puede ser más perjudicial. Evalúa dos spots publicitarios, uno de la marca Punto Matic, que tiene por objetivo concientizar a los hombres sobre las tareas domésticas; sin embargo, este spot muestra al hombre como incapaz de realizar estas tareas sin el apoyo de una mujer. El segundo spot es de la marca P\&G con motivo de los Juegos Olímpicos de Londres 2012. En este se homenajea a las madres por ser las causantes del éxito de sus hijos deportistas, al realizar ellas todas las tareas domésticas. Dicha pieza fue altamente criticada por el Consejo de Andalucía al mostrar una discriminación hacia los padres, pues en ningún momento se hace referencia al apoyo que ellos también aportan. Esta investigación sentó las bases en el presente trabajo para evaluar los spots publicitarios que se seleccionaron.

Por último, se tomó como referencia el trabajo de Galvis (2017), el cual estudia los spots de cerveza con estereotipos de género y el impacto que tienen estos sobre los estudiantes universitarios, desde su percepción por la marca hasta el impacto en las ventas. De los resultados que sobresalen, la mayoría de los estudiantes seguiría consumiendo productos de dicha marca a pesar de que viera un spot publicitario con mensajes ofensivos, ya que genera en ellos sentimientos de diversión en lugar de frustración o ira. Esto podría deberse a la inconsciencia que tienen los estudiantes hacia temas de estudios de género y equidad de género. Este análisis sirvió para terminar de concretar el presente trabajo, gracias a él fue posible implementar una muestra y el análisis de los spots publicitarios para delimitar cuáles funcionan mejor: spots con estereotipos de género o mensajes con equidad de género. 


\section{Marco CONCEPTUAL}

En este marco conceptual se definirán algunos de los conceptos que guiaron la investigación.

\section{Publicidad}

La Asociación Americana de Mercadotecnia (2013) define el marketing como: "los mensajes que hacen las empresas, con el fin de persuadir a un segmento de personas para lograr la afinidad a sus productos, servicios, organizaciones e ideas".

Tiene sus orígenes a partir de la primera revolución industrial, donde a partir de la masificación de los sistemas de producción y consumo, la comunicación comercial quedó a cargo de empresas e instituciones, quienes desconocían los efectos que podrían tener los mensajes de esta en la sociedad (Galvis, 2017). Así, la publicidad se convierte en un fenómeno y factor cultural que configura los hábitos de consumo, gustos, modos de vida, actitudes y estereotipos sociales de los consumidores (Porath et al., 2017).

\section{ESTEREOTIPOS DE GÉNERO}

Los estereotipos son un conjunto de creencias que caracterizan a un grupo social. Los atributos por los cuales se define un grupo social, entre otros, son: la etnia, diferencias socioeconómicas o el género. El género es el conjunto de normas, valores y comportamiento que cada sociedad elabora a partir de la diferencia sexual (De Barbieri, 1991), dividiendo a la sociedad en dos grandes grupos: hombres y mujeres. Los estereotipos de género dictan los roles que hombres y mujeres deben tener, en una sociedad determinada, para poder clasificarse a sí mismos (Luengas y Velandia, 2012).

El machismo, los micromachismos y el sexismo son elementos, dentro de una estructura social, que establecen un orden de género que suscita desigualdades entre hombres y mujeres. De acuerdo a De la Rubia y Ramos (2016): 
El machismo se entiende como una ideología que defiende y justifica la superioridad y el dominio del hombre sobre la mujer; exalta las cualidades asociadas tradicionalmente a lo masculino, como agresividad, independencia y dominancia, mientras estigmatiza las cualidades asociadas tradicionalmente a lo femenino como debilidad, dependencia y sumisión (p. 39).

A su vez, el machismo es uno de los causantes de la violencia hacia la mujer.

Los micromachismos pueden definirse como el conjunto de acciones que muestran tolerancia ante la igualdad de género, pero que implícitamente encubren la necesidad de control y dominación, convirtiéndose en maniobras sumamente sutiles que pasan desapercibidas, dándole una mayor efectividad que a las actitudes de machismo (Ferrer, Bosch, Navarro, Ramis y García, 2008).

Por otro lado, el sexismo hace referencia a las creencias y actitudes en las que se encasilla a la mujer en roles estereotipados debido a su cuerpo biológico (Arnoso, Ibabe, Arnoso y Eldorriaga, 2017). Existen dos tipos de sexismo: en primer lugar, el sexismo benévolo, que ve a la mujer de manera tradicional (ama de casa), enfocándose erróneamente en su calidez y en una falsa baja competencia (Rincón y Velandia, 2013). Se le considera también como un sexismo romántico, puesto que cada acción realizada tanto por hombres como por mujeres se basa en el "supuesto amor" que sienten el uno por el otro, donde, si la mujer actúa como se espera, el hombre le dará una recompensa (Ritzer, 1997); un ejemplo visual de esto son las tradicionales películas de Disney, donde la mujer funge como la damisela en peligro y el hombre como el caballero al rescate. En segundo lugar, puede hablarse de un sexismo hostil, en el que se genera rechazo al comportamiento que se sale de la norma de género (Rincón y Velandia, 2013). Así mismo, se le considera hostil por la discriminación y violencia que sufren las mujeres como forma de "castigo" al no actuar conforme a la norma (Arnoso et al., 2017).

La ideología que se opone a estas actitudes de violencia contra la mujer es la teoría feminista. Esta teoría es mucho más amplia, pero en términos muy generales podría decirse que apunta a cuestionar y analizar las características de la vida social y la 
Jovanna Nathalie Cervantes-Guzmán, José G. Vargas-Hernández y Guillermo Vázquez-Ávila

experiencia humana desde una perspectiva centrada en las mujeres. El género, como categoría de análisis (Scott, 2013), apunta a deconstruir los roles y estereotipos de género con el fin de generar los cambios sociales y culturales que propendan por la equidad en derechos y oportunidades de hombres y mujeres (Ritzer, 1997).

\section{COMUNICANDO A TRAVÉS DE LA PUBLICIDAD}

En 1978 la Unesco reconoció a la publicidad como una actividad de comunicación, la cual forma parte del proceso y del sistema de la misma. Debido a su principal objetivo: "la venta de artículos, productos o servicios", se ve en la necesidad de fomentar ideas y comportamientos en las personas, fomentando para ello un mensaje, siendo el emisor la publicidad y el receptor el público en general (Degrado, 2005). La retroalimentación de esta comunicación la solían medir a través del número de ventas que estaban obteniendo las marcas a causa de una campańa publicitaria; hoy es más sencillo obtener una retroalimentación más directa y real sobre la percepción de los mensajes publicitarios a través de las redes sociales (Mejía, 2011).

La comunicación que maneja la publicidad puede ser tanto explicita como implícita, es decir, por un lado da a conocer las cualidades del producto, así mismo también comunica para qué público o segmento está hecho ese tipo de producto, a partir de ciertas características (mentalidad, costumbres, creencias, aspiraciones, etc.) con las que el consumidor pueda sentirse identificado. Pese a esto, son más los factores que se comunican implícitamente (Rodríguez, 2009). Sin embargo, el problema comienza cuando estos tipos de "estilos de vida" que muestran los mensajes publicitarios se vuelven de interés social, y a partir de esto, las personas comienzan a vivir el mundo copiando estos modelos y tratando de imitarlos, todo por el deseo de querer alcanzar los estereotipos antes mostrados. Por esta razón, se debe ser sumamente cauteloso acerca de los mensajes que se transmitirán al público y afectarán su manera de comportarse y de ver la vida (Arango y Quiceno, 2012). 


\section{¿Cómo AFecta la PUblicidad El COMPORTAMiEnTo Del CONSUMIDOR?}

La publicidad es el puente que conecta a los consumidores con el producto o servicio. Es la estrategia que utiliza la mercadotecnia para lograr su principal objetivo: "las ventas". Para hacerlo codifica un mensaje que pueda afectar el comportamiento de los consumidores (Bassat, 1995). El comportamiento del consumidor es aquella dinámica interna y externa del individuo que sucede en todo el proceso de compra (antes, durante y después), con el objetivo de satisfacer sus necesidades. Para esto busca y evalúa los posibles bienes y servicios que podrían satisfacer dicha necesidad. El comportamiento del consumidor no se termina al ya haber efectuado la compra, sino que le acontece un momento de reflexión sobre el producto o servicio que adquirió y si este cumplió con sus expectativas (Raiteri, 2016).

Cuando se ejecuta un mensaje publicitario, primero se analiza y estudia la audiencia a la que va dirigido. Para ello se toman en cuenta las características y factores individuales del comportamiento del consumidor (Rico, 2011). Dichas características y factores son:

- Factores externos: cultura, clase social, grupos de referencia y familia.

- Factores internos: son las características propias, definen lo que piensa, desea y decide como consumidor.

- Factores sociales: rigen el creer, pensar y actuar de las acciones a causa de la aceptación de terceras personas.

- Características personales: edad, sexo, situación familiar, ocupación y cantidad de ingresos.

- Características psicológicas: percepción, aprendizaje, motivación, actitud, personalidad y estilo de vida. 
Jovanna Nathalie Cervantes-Guzmán, José G. Vargas-Hernández y Guillermo Vázquez-Ávila

Al ya haberse analizado la audiencia a la que va dirigido el mensaje, se crea un escenario que presente personajes y situaciones con dichas características, con el propósito de que el consumidor se sienta identificado o desee ser y vivir una situación como la que se muestra en el comercial (Rico, 2011).

Otras estrategias que suelen utilizarse para persuadir el comportamiento de los consumidores, son: comparación de productos, personificar a los mismos, utilizar metáforas en estos, exagerar las cualidades del producto, usar el doble sentido, ambientación de luz y utilizar un sonido óptimo. El mensaje publicitario se considera exitoso cuando el consumidor muestra la memorización del anuncio, la asociación positiva del producto a un sentimiento placentero, la comprensión del mensaje y un incremento en su comportamiento de compra (Castro Gora, 2008).

\section{CAMbios generacionaleS EN LA PUBLICIDAD}

La mercadotecnia ha agrupado a los consumidores en generaciones, tomando en cuenta únicamente el factor de la edad (Dhanapal, Vashu y Subramaniam, 2015). Se hace así debido a los resultados de investigaciones que demuestran las similitudes de un grupo de personas respecto a sus hábitos de consumo, estilos de vida, condiciones socioeconómicas, físicas y psicológicas (Ramos y Papí, 2012). Estas similitudes son posibles al compartir la era en la que nacieron y los acontecimientos históricos y socioculturales. Se comprenden sus perspectivas respecto a sus valores, su educación, su trabajo y sus aspiraciones en la vida. Se observan también los cambios que han tenido sobre la equidad de género, es decir, la aceptación del rol de la mujer en los ámbitos político, social y laboral, así como otros esquemas familiares (Dormoi, 2016).

Debido a estos factores, las estrategias publicitarias que se manejan para cada uno de estos segmentos generacionales es sumamente diferente, así mismo se debe tomar en cuenta el lenguaje textual, visual y corporal que se utiliza en los spots publicitarios, además del medio a utilizar; es decir, que sea un medio conocido y frecuentado por el público objetivo (Dormoi, 2016). Los consumidores se pueden categorizar en tres 
grupos: baby boomers, generación X y millennials (Dhanapal et al., 2015). Existe una nueva generación llamada "los centennials" (Dormoi, 2016), que aún se encuentra en proceso de ser definida conceptualmente. Se desconoce si existe en la actualidad en México debido al retraso generacional que puede ocurrir de un país a otro (Dhanapal et al., 2015); por tal razón no se presentará en la presente investigación.

\section{Baby boomers}

De acuerdo a Dhanapal et al. (2015), los baby boomers nacieron entre 1946 y 1964, sufriendo los estragos de la Segunda Guerra Mundial. Sin embargo, en Espańa los baby boomers son las personas nacidas entre 1957 y 1977 (IMSERSO, 2009). En cuanto a México, no hay estudios que muestren la fecha exacta de tal generación en el país, visto desde una perspectiva sociológica. Sin embargo, hay estudios sobre la situación de las personas adultas mayores en México; si tomamos las fechas de los estudios de Dhanapal et al. (2015), estas muestra una línea generacional compuesta por personas de 54 años a 72 años. Los baby boomers son considerados la generación de la fuerza económica, social y política. Cambiaron los ideales de la sociedad con movimientos de protesta y revoluciones socioculturales, fueron parte de un sistema educativo tradicional que terminaron rechazando y buscaban satisfacer su necesidad de sentirse útiles y productivos. Para ellos el éxito se traducía en la cantidad de ingresos y bienes materiales que pudieran obtener (Dormoi, 2016).

Existe una escasa presencia de personas mayores en la publicidad mexicana. El giro de las industrias en las que comúnmente aparecen como sujetos en las piezas son salud, alimentación, viajes y ocio. La representación de hombres y mujeres de esta generación continúa presentando una serie de estereotipos, ya que a las mujeres las representa desde la esfera doméstica, mientras que los hombres aparecen en anuncios de tecnología, finanzas, comunicación y electrónica, con una imagen independiente, activa y saludable, mostrándose una imagen confiable gracias a su experiencia (Ramos y Papí, 2012).

Esto podría ser por el hecho de que la población adulta en México corresponde al $16 \%$ de la población total (INEGI, 2015). Además, las empresas podrían basar 
Jovanna Nathalie Cervantes-Guzmán, José G. Vargas-Hernández y Guillermo Vázquez-Ávila

sus anuncios de acuerdo a la generación que representan, reproduciendo roles y estereotipos de género para mantener o aumentar sus ventas.

\section{Generación X}

La Generación X está compuesta por los nacidos entre 1965 y 1980 (Dhanapal et al., 2015). Fueron los primeros en pensar de una manera más individualista y no tanto en la familia. Vivieron los divorcios, dentro de familias monoparentales o donde ambos padres trabajan fuera del hogar, por lo que se les considera como "nińos descuidados". Quieren una mejor calidad de vida; sin embargo, están más interesados en que su trabajo les dé satisfacción que en sacrificar su felicidad por estabilidad económica. Se resisten a seguir la pauta social de sus padres y han decidido retrasar las edades de matrimonio y procreación, en comparación a la corta edad en que sus predecesores lo hicieron (Lerma y Paredes, 2015). De acuerdo a estudios del INEGI, este sector generacional equivale al $25 \%$ de la población total mexicana (2015).

En cuanto a las estrategias de marketing (Asociación Americana de Mercadotecnia, julio de 2013) y publicidad, son muy desconfiados y cuentan con una educación mayor a la de sus predecesores. Antes de hacer una compra investigan acerca del producto y sus especificaciones (Lerma y Paredes, 2015). Fueron influenciados por imágenes audiovisuales y la aparición de la televisión a color. Para ellos es importante que los anuncios tengan un carácter informativo, además de que dejaron de consumir productos únicamente para el hogar y comenzaron a hacerlo de forma individualista (Lerma y Paredes, 2015). Sin embargo, la familia sigue siendo un factor importante para ellos, así que prefieren productos que puedan compartir juntos.

Con ellos se iniciaron las familias monoparentales, razón por la cual los spots que van dirigidos hacia este segmento analizado muestran a madres solteras conviviendo con sus hijos; en otros casos ambos padres están trabajando, usualmente el hombre ocupa los mejores puestos (Lerma y Paredes, 2015). El principal problema de estos spots en cuanto a equidad de género es la insensibilización a los derechos de los hombres como padres de familia amorosos. 


\section{Millennials}

Todas las personas nacidas entre 1981 y el 2000 pertenecen a la generación Y, también conocidas como millennials (o milénicas), se denominan así debido a que la fecha de nacimiento de algunos es cercana al milenio (Dhanapal et al., 2015). Los millennials son reconocidos por ser los nativos digitales dado que su generación estuvo influenciada por la globalización y por haber sido observadores de la evolución tecnológica (Lerma y Paredes, 2015). Se encuentran conectados constantemente a las redes sociales y utilizan más de dos de ellas. En México el promedio son 5 redes sociales por usuario (Asociación de Internet, 2017). Están acostumbrados a las respuestas inmediatas, por lo que no son pacientes dentro de sus medios.

Son consumistas, es decir, gastan más de lo que ahorran (Dormoi, 2016). Sin embargo, son consumidores inteligentes y tienen más herramientas que sus predecesores para investigar. Les gusta que los anuncios vayan dirigidos a ellos y que estos los entretengan, A diferencia de las generaciones anteriores, ellos no se centran en productos para el hogar o la familia sino en aquellos de entretenimiento y comunicación. Siguen siendo un tanto desconfiados, por lo que les gustan las recomendaciones. Las mujeres no tienen prioridad por casarse ni tener hijos, hombres y mujeres están más interesados en crecer profesionalmente, por lo que el consumo académico es importante (Lerma y Paredes, 2015).

Debido a estos hechos las estrategias publicitarias han cambiado, desde la utilización de redes sociales para estar más en contacto con su público objetivo, hasta el uso de influencers; todo esto se verá más adelante en la investigación. Sin embargo, cabe recalcar que los estereotipos de género siguen apareciendo en los spots, y a pesar de que se muestre más la individualidad y autenticidad de los jóvenes de esta generación, se siguen reproduciendo mensajes con micromachismo y sexismo (Lerma y Paredes, 2015).

Las mujeres de esta generación son seguras, decisivas y no aceptan los estereotipos sociales, es así que estudios han dado como resultado que el $86 \%$ de ellas busca ser parte de empresas donde se refleje la diversidad, igualdad e inclusión; tanto hombres como mujeres millennials desafían la autoridad y, por ende, los roles de género 
Jovanna Nathalie Cervantes-Guzmán, José G. Vargas-Hernández y Guillermo Vázquez-Ávila

tradicionales (Dormoi, 2016). Es por ello que en la presente investigación se les seleccionó como sujetos de estudio objetivo.

\section{LA PUBLICIDAD EN REDES SOCIALES}

El surgimiento de Internet y la adopción de nuevas tecnologías por parte de los usuarios trajo consigo un cambio en la manera como se hace publicidad, esto debido a las nuevas generaciones de consumidores y a su necesidad de tener respuestas inmediatas, además de información proactiva y creativa (Rojas, 2013). Estos aspectos se reflejan en las formas de interacción en línea: blogs, wikis y redes sociales; plataformas que deben su éxito a tres factores: 1) capacidad para actualizar información, 2) capacidad de interactuar en tiempo real y, 3) oportunidad para la construcción colaborativa de contenidos (Vallenilla, 2011); además de que dan la libertad al usuario de crear y compartir contenidos sin tener que pagar el diseño de una página web (Sixto García, 2015).

Las redes sociales virtuales han cambiado la forma en que las personas se comunican y se relacionan creando vínculos sin la necesidad de compromisos afectivos (Sixto García, 2015). De acuerdo al estudio de "Hábitos de usuarios de Internet en México 2017 ”, el 70 \% de la población mexicana tiene acceso a Internet, de este porcentaje el $36 \%$ son millennials; es decir, de los 127 millones de mexicanos, 88 millones tienen acceso a Internet, 32 millones pertenecen a la generación milénica y 16 millones son mujeres. De este total, 3 millones pertenecen al estado de Jalisco y el $83 \%$ utiliza Internet para interactuar con redes sociales, además pasan cerca de 2 horas y 58 minutos conectados a ellas. Las 5 redes sociales más utilizadas en México de acuerdo a este estudio son: Facebook (95\%), WhatsApp (93\%), YouTube (72 $\%)$, Twitter (66 \%) e Instagram (59\%). Se descartaron en este estudio WhatsApp porque las empresas no pueden promocionarse en ella, y Twitter porque se consideró que Instagram es más accesible para promocionarse.

\section{Facebook}

Facebook es la red social virtual más utilizada en México (Asociación de Internet, 2017). Esta red se inició en el 2004 como un simple proyecto universitario en 
Harvard, una de las universidades más prestigiadas del mundo; su creador, Mark Zuckerberg de tan solo 19 años de edad, quería crear una red social que fuera diferente a las que ya existían en ese momento, en la que todos los estudiantes de su Universidad estuvieran conectados (Bloomberg, 2013). No obstante, Zuckerberg no se detuvo cuando logró este primer objetivo y junto con sus cocreadores buscaron posicionarse en nuevas universidades. Fue así que en el año 2006 la actualización de Facebook permitió un alcance a nivel mundial, logrando obtener 10 millones de usuarios universitarios (Fernández, 2010). Actualmente Facebook cuenta con más de 2000 millones de usuarios (El Economista, 2017) y la acción se cotiza en la bolsa por 2842 pesos mexicanos (Yahoo Finance, 2018).

Debido al alcance e impacto que tiene Facebook sobre las personas, las empresas han creado estrategias para poder llegar a públicos específicos e incrementar las ventas a través de esta red social (Hubspot, 2017). Las estrategias que utilizan las empresas son las siguientes:

- Crear una página dentro de la red social. El objetivo de esta estrategia es estar en contacto y comunicación con sus respectivos públicos, al obtener likes o generar la comunicación dentro de esta. También se usa como un primer contacto con la empresa, para después redireccionar a los públicos a su página web principal, donde pueden hacer las respectivas compras. Estas pueden generar el mismo contenido que cualquier usuario (fotos, videos, posts, gifs, etc.), sin embargo, crear una página les ofrece opciones extras como la posibilidad de promocionar su contenido, analizar el número de personas que ven sus publicaciones, segmentar a sus determinados públicos y analizar a sus competidores. Los tipos de promoción que se pueden hacer en una página de Facebook son: promoción a publicaciones, promoción continua de una publicación, promoción de la página de Facebook para que más personas la conozcan, conseguir más visitas en el sitio web de la empresa, recibir más mensajes por parte de los usuarios y conseguir más datos de contacto de sus clientes. 
Jovanna Nathalie Cervantes-Guzmán, José G. Vargas-Hernández y Guillermo Vázquez-Ávila

- Facebook para empresas. La segunda opción es desde la página Facebook para empresas, la cual permite crear una campańa publicitaria dentro de esta red social. El tipo de anuncios es diferente a la primera opción, no tiene el objetivo de redireccionar a la página de Facebook de la empresa, sino a la página principal, o a veces solo tiene el propósito de crear una imagen positiva de los productos. Dentro de las opciones promocionales más recomendadas están: conversiones (redirecciona al usuario a la página web o aplicación de la empresa), catálogo (muestra el catálogo de productos de la empresa) y videos. La diferencia de este tipo de videos a los que se publican en la página de Facebook es que estos aparecen cada vez que el usuario está viendo videos de publicaciones sin importar que tengan o no que ver con la empresa; a diferencia de YouTube los usuarios no pueden saltarse estos videos, los cuales duran de 15 a 20 segundos. Algunos cuentan con audio y voice and off, otros solo muestran la imagen promocional. La información recabada de las estrategias se obtuvo en la página oficial para empresas de Facebook. Más adelante se analizarán algunos videos promocionales que se presentan en este medio promocional.

\section{YouTube}

YouTube es la tercera red social más utilizada en México. De acuerdo con el estudio de la Asociación de Internet (2017), el 72 \% de los internautas mexicanos la utilizan. Surgió en el año 2005 a partir de la problemática que tuvieron unos amigos al querer compartir los videos de una fiesta. Ellos eran: Chad Hurley, Steven Chen y Jawed Karim. Crearon YouTube con el eslogan "broadcast yourself", es decir, "transmite tú mismo" (Antolín, 2012). El sitio web creció inesperadamente debido a su sencillez para cargar videos; cualquier persona podía ver y compartir videos originales de todo el mundo. Con el tiempo las marcas se dieron cuenta del poder que tenía promocionarse allí, Google trató de hacer un sitio similar a YouTube pero no tuvo éxito; así que en el año 2006 compró esta plataforma por 1300 millones de euros, alcanzando ese mismo año la cantidad de 100 millones de vídeos vistos por día (Bañuelos, 2008). 
Actualmente YouTube cuenta con más de mil millones de usuarios y cada día estos miran mil millones de horas de videos. De acuerdo a estadísticas de la propia plataforma (2018), su principal segmento son las personas de 18 a 35 años. La manera de hacer publicidad en YouTube es a través de un video previamente cargado, posteriormente se pega la liga de la página del video y se selecciona el mercado al que va dirigido, por ejemplo: amantes de la música. Como YouTube es parte de Google, automáticamente cuando se quiere crear una campańa se abre Adwords y se muestran estadísticos sobre los segmentos que se seleccionaron, además al final del período analiza cuántas vistas se obtuvieron. Toda esta información se extrajo de la página de YouTube para empresas.

Debido al segmento de personas que utilizan dicha plataforma, se seleccionó esta red social para esta investigación. Más adelante se muestra un análisis de videos publicitarios de dicha plataforma.

\section{Instagram}

Instagram no es la red social más utilizada en México, solo el $59 \%$ de los internautas mexicanos la utilizan, sin embargo, se encuentra dentro de las 5 más utilizadas (Asociación de Internet, 2017). Sus creadores, Systrom y Kreiger, eran dos amigos apasionados por la fotografía que comprendían el desarrollo visual que tendría Internet (Madrigal, 2015). El nombre hace referencia a la idea de plasmar cualquier instante de la vida de las personas a través de las fotografías. Instagram se lanzó en 2010 únicamente para la plataforma iOS (sistema operativo móvil de la multinacional Apple Inc.). Después de una semana de su lanzamiento, la plataforma ya contaba con más de 200 mil usuarios, quienes, se estima, publicaban una fotografía por segundo. En 2012 se presentó la versión de Instagram para la plataforma Android, en ese mismo año Facebook compró Instagram por más de 1000 millones de dólares (Madrigal, 2015). Actualmente la aplicación cuenta con más de 700 millones de usuarios, se espera que siga manteniendo este crecimiento acelerado para el 2025. Estudios afirman que la generación milénica prefiere esta aplicación sobre su competidor Snapchat (Expansión, 2017). 
Jovanna Nathalie Cervantes-Guzmán, José G. Vargas-Hernández y Guillermo Vázquez-Ávila

La principal razón que tienen las empresas para invertir en publicidad dentro de esta plataforma, es el tipo de audiencia que posee. En Facebook se pueden encontrar personas de todas las edades, pero en Instagram la gran mayoría son millennials o centennials (Madrigal, 2015). Para contratar los servicios promocionales de esta plataforma, se debe ingresar a una página especial "Instagram para empresas". A continuación, se presentan los servicios que ofrece la página Instagram para empresas:

- Anuncios con foto. Se muestra una fotografía sencilla en formato horizontal, vertical o cuadrada.

- Anuncios por secuencia. Son varias fotografías o videos, el público tiene que deslizar su dedo de derecha a izquierda para encontrar más contenido.

- Anuncios en stories. Pueden ser videos o fotografías. Se localiza en el área de stories.

- Anuncios con video. Los videos pueden ser de hasta 60 segundos, en formato vertical u horizontal, contiene sonido.

La diferencia entre pagar la promoción a hacerlo de manera orgánica, es el número de personas al que se puede llegar. De manera orgánica solo los contactos de la empresa tendrán acceso a ver sus publicaciones, mientras que cuando la empresa invierte, aparecerá en el muro del segmento de audiencia que se escoja. Más adelante se analizarán algunos spots publicitarios que se usan en este tipo de plataforma.

\section{Publicidad CREANdo estereotipos}

La comunicación publicitaria forma parte de la evolución de la sociedad, no solamente crea necesidades, sino también pautas de conducta que generan cambios en los roles sociales (Rodríguez, 2009). El problema no es que las empresas publicitarias desconozcan el impacto que tienen sus piezas en la sociedad, el dilema se inicia cuando los anunciantes desean más impactos en sus ventas, sin importar que las 
ONG reconozcan a la publicidad como amenaza en la condición de género o etnia (Arango y Quiceno, 2012).

Los estereotipos comienzan en la publicidad cuando en el mensaje publicitario se muestra la representación de un grupo que reafirma una característica a nivel cultural, las personas que se sienten identificadas con dicho grupo comenzarán a crear estilos que les ayudarán a definir sus hábitos de comportamiento; de este modo comienzan a imitar los anuncios sobre qué usar y cómo expresarse (Galvis, 2017). Un ejemplo de esto es cuando implícitamente en el mensaje se indica cómo, con una loción específica, se podrá conquistar a una mujer.

Los estereotipos mostrados en los mensajes publicitarios no son inofensivos, alteran la realidad y determinan las creencias y patrones de conducta dentro de la sociedad. Tal es el caso de los roles de género, específicamente el de la mujer, en cuanto el sexismo es considerado cotidiano (Galvis, 2017). En los anuncios se muestran dos tipos de sexismo, el benévolo y el hostil; el primero hace referencia al romanticismo de proteger y adorar a la mujer, haciéndola ver como el complemento del hombre y mostrándola como una persona frágil que necesita cuidados; el segundo se basa en una supuesta inferioridad por parte de las mujeres, donde no solamente se les cosifica sino que marca la existencia de una diferenciación competitiva, según la cual los hombres son los únicos con características para gobernar (Palacios y Rodríguez, 2012).

Esto se evidencia en los mensajes publicitarios en la representación de la imagen masculina con características de competencia y liderazgo, mientras que en la imagen femenina se destacan características como calidez, sociabilidad y comprensión. Esto apoya la baja participación de las mujeres en roles directivos fomentándose en los mensajes publicitarios una inequidad de género; además, podemos encontrar la diferenciación de una imagen independiente por parte de los hombres y una dependiente por parte de las mujeres, con esto se estaría aplicando el termino de sexismo benévolo en la publicidad. También se puede observar cómo la publicidad cosifica a las mujeres utilizándolas simplemente como decoración (Rincón y Velandia, 2013). Existe otro tipo de estereotipo que ha comenzado a mostrarse en los mensajes 
Jovanna Nathalie Cervantes-Guzmán, José G. Vargas-Hernández y Guillermo Vázquez-Ávila

publicitarios: los "micromachismos". Son actitudes estratégicamente planeadas donde explícitamente no se muestra una discriminación como tal, pero ridiculizan la igualdad de género creando nuevos estereotipos de la identidad masculina y femenina, mostrando la incompetencia del hombre para tareas del hogar y el cuidado de los hijos (Suárez, 2013). Son innumerables la cantidad de mensajes publicitarios que no respetan la equidad de género fomentando una sociedad violenta y discriminatoria. El pretexto que utilizan las empresas para defenderse es que la sociedad no se sentiría atraída por el mensaje publicitario pues no se logrará identificar con él (Rincón y Velandia, 2013); sin embargo, en la presente investigación se probará lo contrario y se mostrará la importancia de la creación de leyes publicitarias que eviten este tipo de mensajes.

\section{EL FEMINISMO EN LA PUBLICIDAD}

El feminismo es un movimiento histórico que busca la transformación social para poder lograr una equidad de género entre hombres y mujeres. Gracias a él se ha atacado y denunciado la violencia y la desigualdad de género. No solamente ha conseguido la implementación de leyes para la liberación femenina, sino que también busca la liberación emocional masculina (Scott, 2013). Es decir, el feminismo en la publicidad apunta a una implementación de mensajes sin estereotipos sexistas o micromachismos. Como resultado de esto está la creación de leyes que impidan el auge de estos mensajes. Una región que se ha destacado es Andalucía en Espańa, donde desde el 2007 la Ley General de la Publicidad impide la propagación de mensajes de género discriminatorios, además, hace 25 años se creó un observatorio de la publicidad no sexista para educar a personas de todas las edades sobre este tema y fomentar la denuncia pública para este tipo de mensajes.

En cuanto a México, se encontró una nota periodística de El Excélsior en donde se dice que en el 2013 se aprobó la ley en contra de anuncios con estereotipos sexistas, la cual se establecería en la Ley federal de protección al consumidor, sin embargo no se encontró dicha ley en esta, tampoco está en el Reglamento de la ley general de salud en materia de publicidad; lo único real que tiene México en materia de publicidad 
con mensajes en equidad de género es un manual de sensibilización para incorporar la perspectiva de género en las campañas del gobierno federal (SEGOB, 2011). No obstante, existe la Ley general de acceso a las mujeres por una vida libre de violencia, esta ley además de sus implicaciones de violencia, hace referencia a la comunicación de los medios masivos y su responsabilidad social para erradicar las agresiones en contra de ellas.

La publicidad puede fomentar una consciencia de equidad de género modificando a través de sus mensajes la construcción de una identidad diferente. Algunos anunciantes han comenzado a mostrar pequeños cambios en el concepto de la mujer, pero aún no se han atrevido a romper con el rol tradicional. Está demostrado que los cambios positivos que se hicieron en la publicidad hace algunos ańos, apoyaron el empoderamiento y el desarrollo de las mujeres (López, 2012).

\section{ANÁLISIS DE SPOTS PUBLICITARIOS}

\section{Uber}

Nombre de la campaña: Usa el perfil familiar de Uber

Fecha en que se publicó el spot: 31 de mayo del 2018

Redes sociales: Facebook y YouTube

Duración: 17 segundos

Descripción: al inicio se ve a una mujer saliendo de trabajar mientras su esposo está haciendo la comida, guardando los juguetes de su hija y mirando en su celular que su esposa viene en camino.

Análisis: muestra una familia diferente, donde los roles de mamá y papá están al revés. Se considera un anuncio feminista. 


\section{Cabify}

Nombre de la campaña: \#GoGirlGo

Fecha en que se publicó el spot: 10 de julio de 2017

Redes sociales: Facebook, YouTube e Instagram

Duración: 24 segundos

Descripción: es una mujer que está dentro de un auto y va cantando: "pido mi Cabify, para llegar, porque segura en mi Cabify voy, sola o con amigos”.

Análisis: no es un anuncio feminista ya que hace ver a esta mujer como un ser indefenso; además se estipula que ese comercial está salido de foco después de lo sucedido en Puebla ${ }^{4}$.

\section{Bonafont}

Nombre de la campaña: \#YoSoyAsi

Fecha en que se publicó el spot: 22 de enero de 2018

Redes sociales: Facebook y YouTube

Duración: 1 minuto 6 segundos

Descripción: varias mujeres cantan la canción de Thalía "Yo soy asî". Mientras la cantan se ven diversas mujeres, niñas ganando competencias, una señora mayor

4. "Mara Castilla, la estudiante que desapareció tras salir de un bar y tomar un Cabify en Puebla" (Animal Político, 11 de septiembre de 2017). 
estudiando, una mujer en silla de ruedas disfrutando su vida y una boxeadora, entre otras. Al final el comercial dice: "Aligérate del que dirán y avanza, Bonafont ligera puedes".

Análisis: se considera un comercial feminista debido a la diversidad de mujeres que aparecen en él, además que empodera y reivindica las distintas formas de ser mujer.

\section{Ciel}

Nombre de la campaña: \#ConectaMenteyCuerpo

Fecha en que se publicó el spot: 29 de enero de 2018

Redes sociales: Facebook y YouTube

Duración: 1 minuto

Descripción: se ve a Karla Souza en un set de grabación donde le ofrecen una botella de agua Ciel. Ella la rechaza y enseguida el director le da instrucciones sobre su presentación, Karla comete un error y confunde al villano con el héroe. Después se escucha un voice and off que dice: "Tu cerebro se deshidrata antes de que te des cuenta, toma Ciel”.

Análisis: no se considera un spot feminista a pesar de la figura pública que utiliza, ya que hace ver disminuida su capacidad intelectual.

\section{Coca-Cola}

Nombre de la campaña: \#BestSummerCoke

Fecha en que se publicó el spot: 1 de agosto de 2017 
Redes sociales: Facebook, YouTube e Instagram

Duración: 1 minuto

Descripción: se ve a una pareja que tiene sed, la mujer está manejando y lleva al hombre a un barranco, ella se lanza y él la sigue. Abajo encuentran Coca-Colas.

Análisis: es considerado un spot feminista debido a que la mujer representa roles que usualmente son interpretados por los hombres, como manejar y tener una actitud aventurera.

\section{Sprite}

Nombre de la campaña: Las mujeres lloran por todo

Fecha en que se publicó el spot: 25 de mayo de 2014

Redes sociales: Facebook y YouTube

Duración: 50 segundos

Descripción: Se escucha un voice and off con voz de hombre que dice: "Alguien se pregunta, ¿por qué las mujeres lloran por todo?”. Comienza a dar ejemplos sobre cosas por las que lloran las mujeres, mientras se ejemplifica a través de las imágenes. Al final dice: "Sprite, las cosas como son".

Análisis: está lejos de considerarse feminista, al contrario, es ofensivo para el sexo femenino. Una sátira dramatizada.

\section{Fabuloso}

Nombre de la campaña: Fabuloso Complete 
Fecha en que se publicó el spot: 5 de octubre de 2017

Redes sociales: Facebook y YouTube

Duración: 30 segundos

Descripción: se ve a una pareja limpiando, mientras se escucha una canción. Al final dicen: "Todo en uno para una limpieza profunda".

Análisis: es un spot feminista ya que muestra a ambos miembros de la pareja limpiando la casa, derribando el estereotipo de que es una tarea exclusiva de las mujeres.

\section{Ariel}

Nombre de la campańa: Evita el drama

Fecha en que se publicó el spot: 18 de enero de 2018

Redes sociales: Facebook y YouTube

Duración: 55 segundos

Descripción: aparece una mamá que dice: "Mi hijo cambia de novia como de calzones". Enseguida aparece su hijo quien le reclama porque su camisa de la suerte no está limpia, y le dice: "Con está me ligaba a todas, ahora ninguna me va a pelar, me veo contigo viviendo hasta los 40 como el loco de los gatos". Al final la mamá dice: "estos dramones ya no me pasan desde que descubrí Ariel".

Análisis: muestra estereotipos sociales y machismo, al personificar al hijo como un mujeriego y a la mamá aceptando estas actitudes de su hijo. 


\section{Pinol}

Nombre de campaña: Pinol trapeado diario

Fecha en que se publicó el spot: 25 de mayo de 2012

Redes sociales: Facebook y YouTube

Duración: 50 segundos

Descripción: se ve cómo una mamá necesita salir, así que deja a su bebé con su esposo el cual es Jaime Camil. Ella duda en dejarla con él, pero este la convence. En cuanto se va, la nińa empieza a llorar y Jaime no sabe qué hacer para evitar que continúe con su llanto. Al final abre la botella de Pinol y se da cuenta de que la nińa deja de llorar por el aroma de este producto. Trapea toda la casa con él. Llega la mamá y dice: "Todo bajo control, Pinol, Pinol".

Análisis: en este comercial se puede ver un micromachismo, al hacer ver al padre como incapaz de cuidar a su hija si no está la mamá presente. Por lo tanto, no es considerado un comercial feminista.

\section{ANÁLISIS DEL MODELO}

A continuación se desglosan los conceptos que se presentaron en el modelo. Cada uno de ellos se usó debido a la importancia que tienen dentro del comportamiento de los consumidores, de sus decisiones y compras, además de los aspectos importantes que usan en los comerciales para lograr los objetivos de venta.

\section{Clase social}

División homogénea y duradera de una sociedad. Se ordena jerárquicamente y sus miembros tienen valores, conductas e intereses similares. Tiene que ver con el nivel de ingresos, ocupación y nivel de educación (Raiteri, 2016). 


\section{Cultura}

Conjunto de creencias, arte, costumbres, conocimiento y cualquier capacidad adquirida por el hombre por medio de la sociedad, a través de ella se adquieren valores y creencias (Raiteri, 2016).

\section{Grupos de afinidad}

Grupos que tienen influencia sobre las actitudes, creencias y conductas de una persona (Barboza, 2012).

\section{Familia}

Afecta las creencias y actitudes básicas de los individuos en temas como: religión, política o ambición personal, entre otros (Raiteri, 2016).

\section{Imagen ante la sociedad}

Los roles y el estatus que desempeña una persona ante la sociedad, según la posición que esté desarrollando en este momento (Raiteri, 2016).

\section{Edad}

La edad es importante ya que refleja la etapa del ciclo de vida por el que está cursando esta persona, de esta manera influirá en sus necesidades y en la elección de productos o servicios para la satisfacción de la misma (Raiteri, 2016).

\section{Ocupación}

Es la actividad económica que se realiza para la obtención de ingresos económicos. Usualmente la profesión indica los bienes que se consumirán (Raiteri, 2016). 


\section{Situación económica}

La cantidad de ingresos es importante ya que indica el tipo de producto que puede consumir, además de la actitud que tiene la persona hacia sus ingresos, gastos y ahorro (Raiteri, 2016).

\section{Estilo de vida}

Es la manera en que una persona vive su vida, con actividades, intereses y opiniones (Raiteri, 2016).

\section{Motivación}

De acuerdo a Freud, es un factor interno que impulsa el comportamiento de una persona. La mayoría de estas acciones se realizan de forma inconsciente y tienen que ver con la psicología del individuo.

\section{Personalidad}

Son las características psicológicas que definen a los individuos clasificando los comportamientos y decisiones de las personas (Kothler, 2012).

\section{Percepción}

Es la manera en que un individuo selecciona, organiza e interpreta la información que recibe para ver el mundo a su manera. Esta depende de los estímulos físicos que reciba. Existen tres procesos perceptuales: la atención selectiva, la distorsión selectiva y la retención selectiva (Raiteri, 2016).

\section{Aprendizaje}

Todas las conductas que realizan los seres humanos son aprendidas. La conducta de un individuo se torna gracias a la experiencia o a la práctica que este realice. 


\section{Sexo}

Características fisiológicas y sexuales con las que se diferencian hombres y mujeres (Unicef, 2015).

\section{Actividades}

Acciones que ejecutan los personajes para interpretar un rol social (Kothler, 2012).

\section{Vestuario}

De acuerdo a la Real Academia de la Lengua Española, son los trajes que se utilizan en una representación escénica.

\section{Escenografía}

Conjunto de decoraciones que se realizan dentro de un set de grabación con el objetivo de tener una mejor representación (Suárez, 2013).

\section{Contexto en que se desarrolla el mensaje}

Conjunto de lenguaje no verbal, corporal y situaciones que desglosan el mensaje de manera implícita (Raiteri, 2016).

\section{Medios masivos de comunicación}

Son las formas en que viajan los mensajes de comunicación. Usualmente son la televisión, la radio, el periódico e Internet (Kothler, 2001). 
Jovanna Nathalie Cervantes-Guzmán, José G. Vargas-Hernández y Guillermo Vázquez-Ávila

\section{Metodología}

\section{Diseño de la investigación}

La presente es una investigación con enfoque cualitativo, con alcances exploratorio y correccional. El enfoque cualitativo lo obtiene debido a la recolección de datos sin análisis estadístico, con una descripción detallada de eventos, personas, conductas observadas y su interacción con el objeto de estudio; además de la subjetividad de los datos que puede variar por los individuos y por la manera de analizarlos. Se considera exploratoria porque, a pesar de que existe información previa sobre el objeto de estudio, no se había abordado nunca de la manera en que se estudia en la presente investigación, además de que establece la relación potencial de las variables. Por último, se categoriza con un alcance correccional ya que pretende conocer el grado de asociación entre las variables e intenta predecir el comportamiento de estas al interactuar una con la otra (Baptista, Fernández y Hernández, 2010).

\section{Técnicas e instrumentos de recolección de datos}

Se utilizó la técnica de grupos focales, y dentro de ella, una serie de técnicas proyectivas. Un grupo focal es una estrategia de investigación en la cual se junta un pequeño grupo de personas (de 6 a 8 ) y se les realizan algunas preguntas con el fin de conocer su percepción sobre temas específicos, además de su reacción ante diversas situaciones planteadas (Kotler y Armstrong, 2001). Se realizó un grupo focal con mujeres entre los 25 y 30 años, profesionales o en formación universitaria. En cuanto a las técnicas proyectivas, Chávez (2007) plantea que: "son aquellos instrumentos considerados especialmente sensibles para revelar aspectos inconscientes de la conducta, los cuales permiten provocar una amplia variedad de respuestas subjetivas" (p. 2).

Las técnicas proyectivas utilizadas fueron la observación de videos, donde con base en 9 spots publicitarios se debían contestar una serie de preguntas grupales. Los spots publicitarios que se mostraron fueron de las siguientes marcas: Uber (2018), Cabify (2017), Ciel (2018), Bonafont (2018), Coca-Cola (2017), Sprite, Ariel, Fabuloso y Pinol. La segunda técnica que se utilizó fue un pequeño cuestionario individual que se le entregó a cada participante del grupo focal. 


\section{Análisis y exposición de los resultados}

$\mathrm{Al}$ inicio del grupo focal se preguntó la percepción que consideraban las mujeres sobre las marcas antes de ver los spots publicitarios y la preferencia que tenían entre una marca y otra. El $100 \%$ de las mujeres prefiere a Uber que a Cabify debido a que desconocen la segunda marca y solo han utilizado la primera, sin embargo, una de ellas aceptó que no ha utilizado Cabify ya que le genera sensación de inseguridad a partir de lo ocurrido con la desaparición de la mujer en Puebla. En cuanto a Bonafont y Ciel, el $75 \%$ prefiere Bonafont porque considera que el sabor es mejor además del color de la botella.

En los resultados de Sprite y Coca-Cola, los resultados están divididos 50/50, la mitad considera que la Coca-Cola tiene consecuencias graves para la salud. Para finalizar la primera actividad se les pidió que enumeraran del 1 al 3 las nombres de Pinol, Ariel y Fabuloso, con el fin de conocer el posicionamiento de estas marcas de limpieza. El $75 \%$ considera a Pinol como la mejor marca de las tres, mientras que para el $50 \%$ Ariel es la peor marca.

La segunda actividad fue la observación de cada uno de los spots y comentar las observaciones que fueron relevantes para cada una de ellas. Después se les pidió que calificaran cada uno de los spots del 1 al 9, siendo 1 el mejor spot y 9 el peor. Estos fueron los resultados:

El $75 \%$ acordó que el mejor anuncio fue el de Coca-Cola, el mismo porcentaje consideró que el segundo mejor anuncio fue el de Bonafont.

En cuanto al tercer mejor anuncio, no hubo respuestas similares, cada integrante respondió de manera diferente. Con respecto al cuarto mejor anuncio, el 50 $\%$ contestó que el anuncio de Fabuloso es el que merece ese lugar. El otro $50 \%$ seleccionó a Cabify y a Pinol.

Para el quinto mejor anuncio, el $50 \%$ consideró al de la marca Ariel como el merecedor de esta posición. Las otras integrantes consideran a los anuncios de Uber y Fabuloso como el quinto mejor anuncio. 
Jovanna Nathalie Cervantes-Guzmán, José G. Vargas-Hernández y Guillermo Vázquez-Ávila

En cuanto al peor anuncio de los 9 que se mostraron, el $75 \%$ consideró al de la marca Sprite como el peor anuncio, mientras que el $25 \%$ señaló que el peor anuncio fue el de Ciel.

De las preguntas más relevantes que se hicieron, hubo una acerca de si había cambiado la percepción que tenían de las marcas ya mencionadas. El 75 \% contestó que sí, dejando a Ariel como la peor marca. Con la marca Sprite, el 100 \% cambió la imagen que tenían hacia ella y dejarían de consumirla.

Para finalizar se realizó una dinámica con la herramienta headbands, donde tenían que describir las siguientes palabras: machista, feminista, equidad de género y paridad. El $75 \%$ no tenía una definición correcta de los términos.

\section{ConClusión}

El tema de equidad de género en spots publicitarios sigue siendo algo desconocido en México. A pesar de que ha aumentado el número de marcas que reflejan temas de equidad, empoderamiento femenino y diversidad, las personas apenas lo están comenzando a aceptar y a asociar. En ese sentido, las mujeres solo perciben la violencia de género en los spots publicitarios cuando está de modo muy explícito, por lo que se convierten en blanco para la publicidad con mensajes micromachistas y sexistas implícitos o explícitos-. Aparte de la falta de conocimiento sobre estos temas dentro de la población, no hay definiciones adecuadas sobre feminismo, paridad y equidad dentro de los medios, lo cual puede ser una de las razones por las que las personas estén tardando tanto en aceptar esta realidad.

También se corroboró que el sexismo hostil está desapareciendo, mientras que el sexismo benévolo se está apoderando de la población, provocando que muchas mujeres se vean a sí mismas como princesas indefensas frente a los futuros peligros de la vida. No todo se torna negativo, ya que muchas mujeres están dejando de ver los roles de género que se tenían establecidos en casa y desean una pareja que acepte la división de las tareas del hogar y el apoyo mutuo, además del empoderamiento 
femenino y las metas personales de cada una de ellas por sobresalir académica o laboralmente.

Se necesita generar en el país una mayor consciencia sobre estos temas para que puedan desarrollarse las herramientas legales adecuadas y así proteger los derechos de las mujeres, educando a la sociedad y creando un mundo en el que la equidad de género sea cada vez más visible, dejando atrás la violencia y las discriminaciones para ambos géneros.

\section{REFERENCIAS}

Animal Político. (11 de septiembre de 2017). Mara Castilla, la estudiante que desapareció tras salir de un bar y tomar un Cabify en Puebla. Animal Politico. Recuperado de https:// www.animalpolitico.com/2017/09/mara-castilla-taxy-cabify-cholula-puebla/

Antolín, R. (2012). YouTube como paradigma del video y de la televisión web 2.0 (tesis doctoral). Universidad Complutense de Madrid, Espańa.

Ariel. (18 de enero de 2018). Ariel, evita el drama. [Archivo de video]. Recuperado de https:// www.youtube.com/watch?v=WVC3BvZzAKU

Asociación Americana de Mercadotecnia. (Julio de 2013). Definition of marketing. Recuperado de http://www.ama.org/AboutAMA/Pages/Definition-of-Marketing.aspx

Asociación de Internet. (2017). Estudio sobre los hábitos de los usuarios de Internet en México. Recuperado de https://www.asociaciondeinternet.mx/es/component/ remository/Habitos-de-Internet/13-Estudio-sobre-los-Habitos-de-usuarios

Arnoso, A., Ibabe, I., Arnoso, M., y Elgorriaga, E. (2017). El sexismo como predictor de la violencia de pareja en un contexto multicultural. Anuario de Psicología Jurídica, 27(1), 9-20. Recuperado de https://www.sciencedirect.com/science/article/pii/ S1133074017300156 
Jovanna Nathalie Cervantes-Guzmán, José G. Vargas-Hernández y Guillermo Vázquez-Ávila El impacto de la publicidad con equidad de género en la decisión de compra de los millennials

Bańuelos, J. (2008). YouTube como plataforma de la sociedad del espectáculo. Primera revista digital de América Latina especializada en tópicos de comunicación, 1(1), 1-24.

Baptista, M., Fernández, C., y Hernández, R. (2010). Metodología de la investigación. México D. F., México: McGraw Hill.

Barboza, N. (2012). La influencia del marketing en la toma de decisiones del comprador (trabajo de investigación). Universidad Nacional de Cuyo, Facultad de Ciencias Económicas, Cuyo, Argentina.

Bassat, L. (1995). El libro rojo de la publicidad. México D. F., México: Debolsillo.

Bloomberg. (Productor). (2013). Game changers: Building the Facebook empire. Recuperado de https://www.youtube.com/watch?v=5WiDIhIkPoM

Bonafont. (22 de enero de 2018). Yo soy así. [Archivo de video]. Recuperado de https:// www.youtube.com/watch?v=hC6F2CIpCcg

Cabify. (10 de julio de 2017). Go girl go. [Archivo de video]. Recuperado de https://www. youtube.com/watch?v=OJDOH6I6dRw

Castro Gora, M. E. (noviembre 2008). Influencia de la publicidad en el comportamiento de los jóvenes o adolescentes. Militak's blog. [Mensaje en un blog]. Recuperado de https://militak.wordpress.com/ influencia-de-la-publicidad-en-el-comportamiento-de-los-jovenes-y-a-dolescentes-2/

Chávez, A. (2007). Técnicas proyectivas. Universidad de Colima. Recuperado de https:// comenio.files.wordpress.com/2007/08/tecnicas_proyectivas.pdf

Ciel. (29 de enero de 2018). Conecta cuerpo y mente con Ciel y Karla Souza. [Archivo de video]. Recuperado de https://www.youtube.com/watch?v=sZDMhIFzhnc

Coca-Cola. (1 de agosto de 2017). My Best summer coke. [Archivo de video]. Recuperado de https://www.youtube.com/watch?v=5k8mGU54V2U 
De Barbieri, T. (1991). Sobre la categoría de género. Una introducción teórico-metodológica. En Azeredo, S. y Stolcke, V. (coordinadoras), Direitos reproductivos. Sao Paulo, Brasil: Fundacao Carlos Chagas.

Degrado, D. (2005). Televisión, publicidad y comunicación. Comunicar, 1(25). Recuperado de http://www.redalyc.org/pdf/158/15825078.pdf

Dhanapal, S., Vashu, D., y Subramaniam, T. (2015). Perceptions of the challenges of online purchasing: A study from baby boomers, generation "X" and generation " $Y$ " point of views. Contaduria y Administración, 60(1), 107-132. Recuperado de https://www. sciencedirect.com/science/article/pii/S0186104215000492

Dormoi, A. (2016). En manos de los centenialls, la publicidad para la nueva generación de mujeres (tesis de grado). Universidad de Palermo, Argentina.

Duarte Cruz, J. M., y García-Horta, J. B. (2016). Igualdad, equidad de género y feminismo, una mirada histórica a la conquista de los derechos de las mujeres. Revista CS, (18), 15-66. Recuperado de https://www.icesi.edu.co/revistas/index.php/revista_cs/article/ view/1960/2827

El Economista. (2017). Facebook alcanza 2000 millones de usuarios. El Economista. Recuperado de https:/www.eleconomista.com.mx/tecnologia/Facebook-alcanza-los2000-millones-de-usuarios-20170627-0013.html

Expansión. (2017). Instagram llega a 700 millones de usuarios ¿Superará a Snapchat? CNN en español. Recuperado de http://cnnespanol.cnn.com/2017/04/26/ instagram-llega-a-700-millones-de-usuarios-superara-a-snapchat/

Fabuloso. (5 de octubre de 2017). Comercial Fabuloso Complete Colombia. [Archivo de video]. Recuperado de https://www.youtube.com/watch?v=BlB5ZoOLwm8

Facebook para empresas. (26 de marzo de 2018). Administrador de anuncios. Recuperado de https://www.facebook.com/business/ 
Jovanna Nathalie Cervantes-Guzmán, José G. Vargas-Hernández y Guillermo Vázquez-Ávila El impacto de la publicidad con equidad de género en la decisión de compra de los millennials

Fernández, L. (2010). Origen y evolución de Facebook. Recuperado de http://ict.edu.ar/ renovacion/wp-content/uploads/2015/03/diagnostico-2015-nticx-actic-2.pdf

Fernández, A. (2017). La influencia de los roles de género en la publicidad televisiva en el comportamiento de género (tesis de licenciatura). Universidad de Sevilla, Espańa.

Ferrer Pérez, V. A., Bosch Fiol, E., Navarro Guzmán, C., Ramis Palmer, M. C., y García Buades, M. E. (2008). Los micromachismos o microviolencias en la relación de pareja. Una aproximación empírica. Anales de Psicología, 24(2), 341-352. Recuperado de http:// www.redalyc.org/pdf/167/16711589018.pdf

Galvis, R. (2017). La publicidad con mensaje estereotipado: análisis del efecto en la imagen de marca y la intención de compra, un estudio en universitarios (tesis de maestría). Universidad de Guadalajara, México.

García, Y., Manzano, J., y Parreño, J. (2012). La publicidad actual: retos y oportunidades. Pensar la Publicidad, 6(2), 327-343.

Hubspot. (2017). Guía básica de la publicidad en redes sociales. Recuperado de https://www. mediaprime.cl/knowledge-files/publicidad-en-redes-sociales.pdf

IMSERSO. (2009): Informe 2008. Las personas mayores en España. Colección Documentos, Serie Documentos Estadísticos, n. ${ }^{\circ} 22019$. Madrid, España: IMSERSO.

Instagram para empresas. (27 de marzo de 2018). Consolida tu empresa en Instagram. Recuperado de https://business.instagram.com/advertising/\#types

INEGI. (2015). Mujeres y hombres en México. Recuperado de http://internet.contenidos. inegi.org.mx/contenidos/Productos/prod_serv/contenidos/espanol/bvinegi/productos/ nueva_estruc/702825075019.pdf

Instituto Andaluz de la Mujer. (2007). Unidad de Igualdad de Género. Rincón Autodidacta. Recuperado de https://www.juntadeandalucia.es/institutodelamujer/ugen/modulos/ Leyes/docs/PIGA.htm 
Kotler, P., y Armstrong, G. (2001). Marketing. México D. F., México: Pearson Educación.

Lerma, C., y Paredes, Y. (2015). Objetos simbólicos de consumo y su relación con la construcción de identidad de las generaciones de consumidores en la ciudad de CaliColombia. Revista global de negocios, 3(6), 75-88. Recuperado de https://papers.ssrn. $\mathrm{com} /$ sol3/papers.cfm?abstract_id=2659327

López, S. (2012). Publicidad e identidades, cuando la publicidad favorece la igualdad de género. Actes de congénere: la representació de génere a la publicitat del segle XXI, 1-14.

Luengas, H., y Velandia, A. (2012). Nivel de sexismo en consumidores y su valoración sexista de la publicidad. Suma Psicológica, 19(2), 75-88. Recuperado de http://www.scielo.org. co/pdf/sumps/v19n2/v19n2a06.pdf

Madrigal, C. (2015). Instagram como herramienta de comunicación publicitaria: el caso de made with lof (tesis de pregrado). Universidad de Sevilla, Sevilla, España.

Martínez, G. (2017). La generación X, producto del conservadurismo. Canadá y México durante la era Harper. México D. F., México: CISAN, UNAM.

Mejía, J. (2011). De la persuasión a la relación: convenciendo a la publicidad de su fin comunicativo. Signo y Pensamiento, 31(59), 78-91.

Moral, J., y Ramos, S. (2016). Machismo, victimización y perpetración en mujeres y hombres mexicanos. Estudios sobre las culturas contemporáneas, 21(43), 37-66. Recuperado de https://www.redalyc.org/articulo.oa?id=31646035003

Muriel, C. (27 de abril de 2018). ¿Qué es un spot publicitario y qué tipos hay? [Mensaje en un blog]. Recuperado de https://solomarketing.es/ que-es-un-spot-publicitario-y-que-tipos-hay/

Observatorio Andaluz de la Publicidad no Sexista. (30 de marzo de 2018). Regulación normativa. Recuperado de http://www.juntadeandalucia.es/institutodelamujer/index.php/ observatorio-andaluz-de-publicidad-no-sexista/regulacion-normativa\#cubeRandom 
Jovanna Nathalie Cervantes-Guzmán, José G. Vargas-Hernández y Guillermo Vázquez-Ávila El impacto de la publicidad con equidad de género en la decisión de compra de los millennials

Palacios, S., y Rodríguez, I. (2012). Sexismo, hostilidad y benevolencia. Género y creencias asociadas a la violencia de pareja. Innovación para el progreso social y sostenible, pp. 411-431. XVII Congreso de Estudios Vascos. País Vasco.

Pinol. (25 de mayo de 2012). Nuevo Pinol trapeado diario. [Archivo de video]. Recuperado de: https://www.youtube.com/watch?v=OfS9RiGH66U

Porath, W., Vergara, E., Gómez, P., y Labarca, C. (2017). Cambios en la presentación de los personajes de la publicidad del retail en Chile en un contexto de modificaciones en la lógica de consumo asociadas a transformaciones socioculturales (1997-2013). Comunidad y Sociedad, (29), 203-225. Recuperado de http://www.scielo.org.mx/pdf/ comso/n29/0188-252X-comso-29-00203.pdf

Quiceno, B. y Arango, C. (2012). Valores culturales en la publicidad exterior: entre la intención comunicativa y la apropiación del mensaje. Anagramas: Rumbos y sentidos de la comunicación, 10(20), 95-108. Recuperado de https://revistas.udem.edu.co/index.php/ anagramas/article/view/625/566

Raiteri, M. (2016). El comportamiento del consumidor actual. Trabajo de investigación. Universidad Nacional de Cuyo, Argentina.

Ramos Soler, I., y Papí Gálvez, N. (2012). Personas mayores y publicidad. Representaciones de género en televisión. Estudios sobre Mensajes Periodísticos, 18(3), 753-762. Recuperado de http://revistas.ucm.es/index.php/ESMP/article/viewFile/40954/39204

Rico, J. (2011). La influencia de la publicidad en la toma de decisión de compra en los productos light en el consumidor. Revista Observatorio Calasanz, 3(5), 261-270.

Rincón, J., y Velandia, A. (2013). Estereotipos y roles de género utilizados en la publicidad transmitida a través de la televisión. Universitas Psychologica, 13(2), 517-527. Recuperado de http://www.redalyc.org/html/647/64732221010/

Ritzer, G. (1997). Teoría sociológica contemporánea. México D. F., México: McGraw Hill. 
Rodríguez, A. (2009). La publicidad como fenómeno comunicativo durante la guerra civil española. Revista Latina de Comunicación Social, 12(64), 29-42. Recuperado de http:// www.redalyc.org/pdf/819/81911786003.pdf

Rojas, I. (2013) La publicidad en las redes sociales: impulso a las microempresas en crecimiento. Ambiente Macroeconómico 4(2), 1-13.

Schudson, M. (1986). Advertising the uneasy persuasión. Journal of Advertising, 14(4).

Scott, J. W. (2013). El género: una categoría útil para el análisis histórico. En M. Lamas (ed.), El Género. La construcción cultural de la diferencia sexual (4th ed., pp. 265-302). México D. F., México: Programa Universitario de Estudios de Género y Miguel Ángel Porrúa.

SEGOB. (2011). Publicidad con equidad, manual de sensibilización para incorporar la perspectiva de género en las campañas del gobierno federal. México D. F., México. Recuperado de http:/gobernacion.gob.mx/work/models/SEGOB/Resource/946/5/ images/SENSIBILIZACION(1).pdf

Sixto García, J. (2015). Desarrollo de las redes sociales como herramienta de marketing. Estado de la cuestión hasta 2015. Anagramas, 13(26), 179-196. Recuperado de https:// revistas.udem.edu.co/index.php/anagramas/article/view/1188/1147

Sprite. (25 de mayo de 2014). ¿Por qué las mujeres lloran por todo? [Archivo de video]. Recuperado de https://www.youtube.com/watch?v=3CVC-LNx_ps

Suárez, J. (2013). El micromachismo en la publicidad. Nuevas estrategias para viejos estereotipos: "mi marido me ayuda" y "el elogio de la maternidad". Pensar la publicidad, 7(2), 239-251. Recuperado de https://idus.us.es/xmlui/bitstream/handle/11441/40935/El\%20micromachismo. pdf? sequence $=1$ \&isAllowed $=y$

Uber. (Febrero de 2018). Usa el perfil familiar de Uber. [Archivo de video]. Recuperado de https://www.facebook.com/UberMexico/videos/997033887125820/ 
Jovanna Nathalie Cervantes-Guzmán, José G. Vargas-Hernández y Guillermo Vázquez-Ávila El impacto de la publicidad con equidad de género en la decisión de compra de los millennials

Unicef. (2015). The big picture. Igualdad de género. Recuperado de https:/www.unicef.org/ spanish/gender/3984_bigpicture.html

Vallenilla, R. (2011). Redes sociales y consumidores jóvenes, ¿es creíble la comunicación de marcas? Debates IESA, 16(4), 54-58.

Yahoo Finance. (26 de marzo de 2018). Facebook inc. Recuperado de https://finance.yahoo. $\mathrm{com} / \mathrm{m} / 674053 \mathrm{~d} 6-9 \mathrm{~b} 00-3185-\mathrm{b} 8 \mathrm{c} 0-6 \mathrm{~b} 276 \mathrm{bca} 682 \mathrm{~d} /$ ftcconfirms-it-is.html

YouTube. (27 de marzo de 2018). Acerca de YouTube, Prensa. Recuperado de https://www. youtube.com/intl/es-419/yt/about/

YouTube. (27 de marzo de 2018). Publica anuncios en la plataforma que todos miran. Recuperado de https://www.youtube.com/intl/es-419/yt/advertise/ 